\title{
Correlation of follicular steroid hormone profiles with ovarian cyclicity in sows
}

\author{
G. O. Babalola and B. H. Shapiro \\ Department of Animal Biology, Laboratories of Biochemistry, School of Veterinary Medicine, \\ University of Pennsylvania, 3800 Spruce Street, Philadelphia, PA 19104-6048, U.S.A.
}

\begin{abstract}
Summary. Ovaries were obtained from sows immediately after slaughter and were morphologically assigned to different stages of the ovarian cycle. Follicular fluid contained in the predominating follicles was analysed for ten steroid hormones by a multiple, simultaneous radioimmunoassay technique. The steroids measured were pregnenolone, progesterone, 20 $\alpha$-dihydroprogesterone, 17 $\alpha$-hydroxyprogesterone, androstenedione, $5 \alpha$-dihydrotestosterone, dehydroepiandrosterone, testosterone, oestrone and oestradiol-17 $\beta$.

The concentrations of the steroids remained relatively low during the luteal stages until the mid-follicular stage when ovaries contained predominantly small to mediumsized $(<5.0 \mathrm{~mm}$ in diam.) follicles. With the exception of $5 \alpha$-dihydrotestosterone concentrations, which remained low regardless of the size of the follicles or the stage of the cycle, the concentrations of all the steroids were significantly elevated in the transition from the mid- to late follicular stage, a period when the ovaries contained mainly large (6-10 $\mathrm{mm}$ diam.) follicles. Follicles at the ovulatory stage exhibited a profound decline in the concentrations of androgens and oestrogens. In contrast, the magnitude of decline in the levels of 3 progestagens, i.e. pregnenolone, progesterone and $17 \alpha$-hydroxyprogesterone, was much less than that for androgens and oestrogens, while the concentration of $20 \alpha$-dihydroprogesterone was actually elevated in the ovulatory follicles.

The present results agree with those of earlier studies which measured fewer steroids in follicles obtained by repeated and sequential laparotomies of sows during spontaneous cycles. In contrast, these hormone results differ from those using the PMSG/ hCG-stimulated ovary, suggesting that such ovaries may not be a completely valid model for ovarian steroid hormone metabolism in the normally cycling sow.
\end{abstract}

Keywords: steroids; ovary; cyclicity; pig

\section{Introduction}

There is evidence to suggest that antral steroids play a key role in the process of growth and maturation of the follicle (Sanyal et al., 1974, McNatty et al., 1979), in the ovulatory process (Lipner \& Wendelken, 1971; Rondell, 1974 Mori et al., 1977), and in the regulation of their own synthesis (Leung \& Armstrong, 1980; Gower \& Cooke, 1983). Despite these important emerging roles for follicular steroid hormones, and the increasing use of pig ovaries in reproductive studies, there are incomplete data on the profiles of steroid hormones in the ovarian follicle and their relationships to follicular development or the oestrous cycle in sows.

Steroid hormone production in pig follicles has been studied for ovaries obtained from sows with accurately monitored spontaneous oestrous cycles (Eiler \& Nalbandov, 1977; Pzala et al., 1985), or from gilts treated with PMSG/hCG to stimulate folliculogenesis (Ainsworth et al., 1980). 
While the latter model is undoubtedly useful in studying a number of follicular factors including steroids, it may not, in many respects, represent the natural state. For example, Aguado \& Ojeda (1985) have reported that the ovarian steroidogenic response to hCG differed markedly between normal and PMSG-primed rats. Also, certain inconsistencies exist in the concentrations of follicular steroid hormones measured in the two live pig models. Using non-specific antisera, the concentrations of hormone groups designated as total progestagen, androgen and oestrogen increased with the development of follicles in spontaneously cycling animals, until close to ovulation when all steroid values declined precipitously (Eiler \& Nalbandov, 1977). In contrast, progesterone concentration increased significantly close to ovulation and androgen concentrations remained unchanged throughout follicular development in the PMSG/hCG-stimulated follicles (Ainsworth et al., 1980).

In view of these inconsistencies, we have used slaughterhouse ovaries to examine further the relationship between follicular steroid hormone content and ovarian cyclicity. Although a major criticism of the use of abattoir-derived ovaries relates to difficulties in accurate assessment of the stage of the animal's oestrous cycle, the problem can be addressed by comparing detailed analyses of the day-to-day morphological changes of the pig ovary in relation to the oestrous cycle (Akins \& Morrissette, 1968; McDonald, 1975). Unfortunately, previous studies utilizing slaughterhouse ovaries (Chang et al., 1976; Flemming \& McGaughey, 1982) did not relate steroid hormone concentrations to the stages of the cycle, but rather to absolute sizes of the follicles. The aim of the present study was to provide a more comprehensive profile of steroid hormones than has previously been reported for the developing pig ovarian follicle and to correlate these findings with the morphologically determined functional stages of the ovarian cycle.

\section{Materials and Methods}

\section{Source of animals and sample collection}

Ovaries were obtained from female pigs within $1 \mathrm{~h}$ of slaughter at a local abattoir and brought to the laboratory in ice-cold physiological saline $(0.9 \%(\mathrm{w} / \mathrm{v}) \mathrm{NaCl})$. Only ovaries with morphological evidence of at least one recent cycle were selected for the study, i.e. ovaries that contained fresh or regressing corpora lutea in addition to developing Graafian follicles with or without corpora albicantia. Ovaries with developing Graafian follicles, corpora albicantia but no corpora lutea were eliminated from the study, since it was not possible to know whether these sows were cycling normally.

According to their gross morphology (Akins \& Morrissette, 1968; McDonald, 1975), ovaries were assigned to functional stages of the oestrous cycle by carefully examining them for corpora haemorrhagica, corpora lutea, corpora albicantia and developing follicles, and their relative numbers, sizes, colours, consistencies and degree of blood supply. The luteal and follicular phases were each subdivided into early, mid- and late stages. Some late follicular-stage ovaries had large follicles which were estimated to be close to ovulation based on their gross morphology, including consistency, increased distensibility, thinning of 'ovulatory' points and other features that have been described by earlier workers (Hunter, 1967; Rondell, 1974; Fernandez-Pardal et al., 1986). These ovaries were classified as 'ovulatory' or oestrous-stage ovaries. The criteria for the classification of ovaries into various stages are summarized in Table 1.

Follicles from each of the seven ovarian groups were quickly and carefully dissected out from extraneous tissues. Follicles from each pair of ovaries were then separated into small $(<0.4 \mathrm{~cm}$ diameter), medium $(0.4-0.6 \mathrm{~cm}$, diameter) and large $(0.61-1.1 \mathrm{~cm}$ diameter) groups, by quickly estimating their sizes with a millimeter rule. Atretic follicles identified by using the macroscopic criteria established for sheep follicles (Moor et al., 1978) and validated for the pig follicle (Maxson et al., 1985) were excluded from the study. (Atretic follicles were grossly whitish, opaque or translucent, and much less vascularized than healthy follicles. They contained, at the extreme, white, often milky materials, presumably degenerated membrana granulosa cells.)

The predominant follicles, i.e. those follicles that constitute the larger size category and which make up more than $50 \%$ when compared to the next large size category of follicles in a pair of ovaries, were then identified. Due to time constraints, only $30-50 \%$ of the predominant follicles were randomly chosen to be carefully measured with a caliper graduated to $0.01 \mathrm{~mm}$. Without exception, follicles measured by caliper remained within the same 'size group' initially established with a millimeter ruler.

All follicles in the predominating size category in a pair of ovaries were punctured by scissors and cut and the fluid was allowed to flow into a clean vessel. The follicular fluid was aspirated with a needle and syringe and pooled for each pair of ovaries, i.e. per animal. The follicular fluid was centrifuged at $1000 \mathrm{~g}$ for $5 \mathrm{~min}$ at $4^{\circ} \mathrm{C}$ to remove cellular materials, and the supernatant was stored at $-20^{\circ} \mathrm{C}$ before radioimmunoassays. 


\section{Analytical procedures}

Extraction and chromatography. The follicular fluid was diluted 10-20 times with phosphate buffer and aliquants of the diluted samples were taken for the extraction of progestagens, androgens and oestrogens. Sephadex LH-20 (Pharmacia Fine Chemicals, Piscataway, NJ, U.S.A.), 2 g each for progestagens and androgens and $1.0 \mathrm{~g}$ for oestrogens, was swelled overnight in the eluting solvents and packed in $0.9 \times 18.0 \mathrm{~cm}$ glass columns (NEN Research, Boston, MA, U.S.A.). After incubation with tracer amounts of appropriate tritiated steroids (1000-1500 c.p.m.), follicular fluid was extracted twice in 5 volumes of diethyl ether. Extracts were redissolved in $0 \cdot 2 \mathrm{ml}$ eluting solvent and chromatographed on Sephadex LH-20 using iso-octane:benzene:methanol (85:15:5 (by vol.) for progestagens, $85: 10: 5$ (by vol.) for androgens) and benzene:ethyl acetate:methanol (90:5:5 (by vol.)) for oestrogens (Carr et al., 1971). Recoveries obtained after extraction and chromatography varied between 60 and $90 \%$.

A sequential mixture (according to order of elution) of carbon-14 and tritium-labelled androgen, oestrogen and progestagen standards was chromatographed each time to monitor the three chromatography systems.

Radioimmunoassay. Tritiated steroids were obtained commercially. $\left[1,2,6,7-{ }^{3} \mathrm{H}\right]$ progesterone (sp. act. $85 \mathrm{Ci} / \mathrm{mmol}$ ), 17ß-hydroxy $\left[1,2-{ }^{3} \mathrm{H}\right] 5 \alpha$-androstane-3-one (sp. act. $45 \mathrm{Ci} / \mathrm{mmol}$ ), $\left[1,2,6,7-{ }^{3} \mathrm{H}\right]$ testosterone (sp. act. $80 \mathrm{Ci} / \mathrm{mmol}$ ), and $\left[2,4,6,7-{ }^{3} \mathrm{H}\right]$ oestradiol- $17 \beta$ (sp. act. $105 \mathrm{Ci} / \mathrm{mmol}$ ) were purchased from Research Products International Corp. (Mount Prospect, IL, U.S.A.). $\left[1,2,6,7-{ }^{3} \mathrm{H}\right]$ Androst-4-ene-3, 17 -dione (sp. act. $85 \mathrm{Ci} / \mathrm{mmol}$ ) and $\left[7-{ }^{3} \mathrm{H}(\mathrm{N})\right]$ pregnenolone (sp. act. $13 \mathrm{Ci} / \mathrm{mmol}$ ) were obtained from NEN Research (Boston, MA, U.S.A.). $20 \alpha-\left[1,2-{ }^{3} \mathrm{H}(\mathrm{N})\right] \mathrm{Hydroxypreg-4-ene-3-one} \mathrm{(sp.}$ act. $57 \cdot 5 \mathrm{Ci} / \mathrm{mmol}$ ), $17 \alpha$-hydroxy $\left[1,2,6,7-{ }^{3} \mathrm{H}(\mathrm{N})\right]$ progesterone (sp. act. $55 \mathrm{Ci} / \mathrm{mmol}$ ), dehydro[1,2,6,7- $\left.{ }^{3} \mathrm{H}\right]$ epiandrosterone (sp. act. $61 \mathrm{Ci} / \mathrm{mmol}$ ) and $\left[2,4,6,7-{ }^{3} \mathrm{H}\right]$ oestrone (sp. act. $83 \mathrm{Ci} / \mathrm{mmol}$ ) were all products of Amersham Corporation (Arlington Heights, IL, U.S.A.).

All steroid antisera were purchased from Radioassay Systems Laboratories, Inc. (Carson, CA, U.S.A.) except for the 20a-dihydroprogesterone antiserum which was obtained from Scantibodies, Inc. (Lakeside, CA, U.S.A.). Specificity data as presented by the companies were found to be satisfactory, except for the following cross-reactivities $(\%)$ which were considered to be high: testosterone versus $5 \alpha$-dihydrostestosterone, $18 \cdot 75 \%$; $5 \alpha$-dihydrotestosterone $v s$ testosterone, $22.7 \%$; $5 \alpha$-dihydrotestosterone $v s$ androstenedione, $2.4 \%$; androstenedione $v s$ dehydroepiandrosterone, $5 \cdot 42 \%$; pregnenolone vs progesterone, $1.5 \%$; progesterone $v s 17 \alpha$-hydroxyprogesterone, $1.4 \%$. All others were $<0.8 \%$. However, a procedure incorporating the chromatography step was adopted to enhance further the specificity of some of the assays with appreciably cross-reacting antibodies, and also to improve the yield of samples, thereby permitting measurement of multiple steroids in single small volumes of follicular fluid.

Steroid standards were purchased from Sigma Chemical Company (St Louis, MO, U.S.A.) except for pregnenolone and dehydroepiandrosterone which were obtained from Steraloids (Wilton, NH, U.S.A.). All other chemicals and reagents were of analytical grade and were obtained from Fisher Scientific (King of Prussia, PA, U.S.A.), unless otherwise stated. Assay conditions were worked out in our laboratory based on the methods of Abraham et al. (1975). In all radioimmunoassays, bound steroids were separated from free with Dextran-charcoal (Norit-A; Dextran T70, Pharmacia Fine Chemicals, Piscataway, NJ, U.S.A.) and the entire supernatant (bound fraction) was counted in an LKB 1218 Rackbeta Liquid Scintillation Counter. Sufficient counts were accumulated to keep the counting error below $5 \%$.

The sensitivity of the standard curve was taken as the least hormone concentration that was significantly different from zero at the $95 \%$ confidence limit (Abraham, 1975). Within-assay and between-assay coefficients of variation were estimated from 5 quality control samples analysed as quintuplicates in at least 5 different assays using statistics as enumerated by Rodbard (1974). To estimate the accuracy of the method, 4 sets of quality control samples were prepared by adding all 10 steroids to steroid-free pig serum at levels of $0 \cdot 1,1 \cdot 0,10.0$ and $100 \cdot 0 \mathrm{ng} / \mathrm{ml}$. The samples were carried through the system like the follicular fluid test samples, and recovery percentage was estimated at the end of the entire procedure. Due to limited amounts of available charcoal-stripped follicular fluid only 1 set, i.e. the $10 \mathrm{ng} / \mathrm{ml}$ sample, was used in the validation assays. Results of 4 assays repeated 3 times on this sample did not differ significantly from that obtained with $10 \mathrm{ng} / \mathrm{ml}$ charcoal-stripped pig serum.

The values for the sensitivity of the standard curve (pg/tube), within-assay coefficient of variation ( $\%)$, betweenassay coefficient of variation (\%) and mean accuracy (\% recovery), respectively, were as follows: pregnenolone, $20 \cdot 0$, $6 \cdot 4,13.8$ and $78 \cdot 5$; progesterone, $10 \cdot 0,4 \cdot 5,13 \cdot 3$ and $101 \cdot 9: 20 \alpha$-dihydroprogesterone, 10.0, 5.6, 11.9 and $89 \cdot 4 ; 17 \alpha-$ hydroxyprogesterone, $5 \cdot 0,8 \cdot 9,10.5$ and $92.5 ;$ androstenedione, $10 \cdot 0,3 \cdot 5,7 \cdot 5$ and $81 \cdot 6 ; 5 \alpha$-dihydrotestosterone, $10 \cdot 0$, $4 \cdot 9,12 \cdot 5$ and $76 \cdot 9$; dehydroepiandrosterone, $5 \cdot 0,4 \cdot 6,5 \cdot 9$ and $86 \cdot 9$; testosterone, $5 \cdot 0,6 \cdot 9,10 \cdot 3$ and $76 \cdot 2$; oestrone, $10 \cdot 0$, $5 \cdot 3,14 \cdot 4$ and $90 \cdot 5 ;$ and oestradiol $-17 \beta, 5 \cdot 0,4 \cdot 8,8 \cdot 3$ and $97 \cdot 2$.

\section{Statistical procedures}

The raw data were subjected to analysis of variance (ANOVA), and individual $t$ tests were carried out to compare pairs of means using the mean square error from the ANOVA.

\section{Results}

The criteria (Table 1) for categorizing ovaries into different stages were developed based on the morphological changes which have been shown to be characteristic of pig ovaries during the 
oestrous cycle (McDonald, 1975). Due to their extremely small size, follicles in early luteal-phase ovaries were not analysed. The follicles in each group gradually increased in mean size (diameter) with the progression of the ovarian cycle (Table 2). Thus, the mean diameters of the predominating follicles were directly related to the stage of the ovarian cycle. Generally, the early luteal to mid follicular stage ovaries had essentially small to medium-sized follicles ( $2-6 \mathrm{~mm}$ diameter) while late follicular and ovulatory ovaries contained large follicles $(6.0-11.0 \mathrm{~mm}$ diameter).

\section{Preovulatory follicles}

Progestagens. Progesterone concentrations in the early follicular-phase ovaries (Fig. la) were significantly higher $(P<0.05)$ than those in the mid- or late luteal stages. A similarly significant decline was found in the concentration of progesterone in mid-follicular compared to early follicular ovaries. There were no significant changes in the concentrations of follicular pregnenolone, $20 \alpha-$ dihydroprogesterone and $17 \alpha$-hydroxyprogesterone from the mid-luteal stage to the mid-follicular stage, an interval representing a period when the ovaries had small to medium-sized follicles. Large follicles in late follicular-stage ovaries contained significantly higher concentrations of all progestagens $(P<0.001)$ than in the preceding stages.

Androgens. The mean concentrations of all androgens (Fig. $1 \mathrm{~b}$ ) remained very low and unchanged during the early stages of the ovarian cycle. However, the transition from mid- to late follicular stage witnessed a dramatic increase in the levels of androstenedione (6-fold), testosterone (7-fold) and dehydroepiandrosterone ( 40 -fold). In contrast, low concentrations of $5 \alpha$-dihydrotestosterone were maintained in the largest follicles. Androstenedione was the major androgen in the medium and large follicles.

Oestrogens. Cyclic changes in follicular fluid concentrations of oestrone and oestradiol-17 $\beta$ (Fig. 1c) followed a pattern similar to that found for the major androgens. The largest concentrations of both oestrogens were found in the large follicles from ovaries in the late follicular stage, with oestradiol-17 $\beta$ being more abundant than oestrone at this time.

\section{Ovulatory follicles}

Ovaries in the ovulatory stage had all the extrafollicular features of late follicular stage ovaries. They were distinguished from the latter by the morphology of their follicles and, in 2 out of 4 animals, the presence of 2 freshly ruptured follicles (corpora haemorrhagica). Specifically, ovulatory follicles were generally less vascularized, slightly paler in colour and appeared to have lower intrafollicular pressure than did large preovulatory follicles. Although the ovulatory follicles were similar in size to large follicles in late follicular stage ovaries, they contained significantly $(P<0 \cdot 001)$ lower concentrations of all androgens and oestrogens, as well as of pregnenolone, progesterone and 17 $\alpha$-hydroxyprogesterone (Fig. 1). However, the reduction in the values of the progestagens (45-70\%) was much less dramatic than that of androgens and oestrogens $(>90 \%)$. Furthermore, $20 \alpha$-dihydroprogesterone concentrations did not decline but were significantly $(P<0.001)$ elevated in the ovulatory follicles when compared to late follicular-stage preovulatory follicles.

\section{Discussion}

The pig ovary has characteristics which make it especially suitable for certain reproductive studies. It has multiple ovulations, hence many follicles develop and reach maturity together, most ovarian structures are large and can be isolated with little difficulty and without the aid of a microscope, and the material can be obtained at the abattoir. A major criticism of the use of slaughterhouse materials concerns the difficulty of accurately determining the day of the oestrous cycle of the donor animal. However, in studies in which this factor need not be-accurately defined to the day, an 


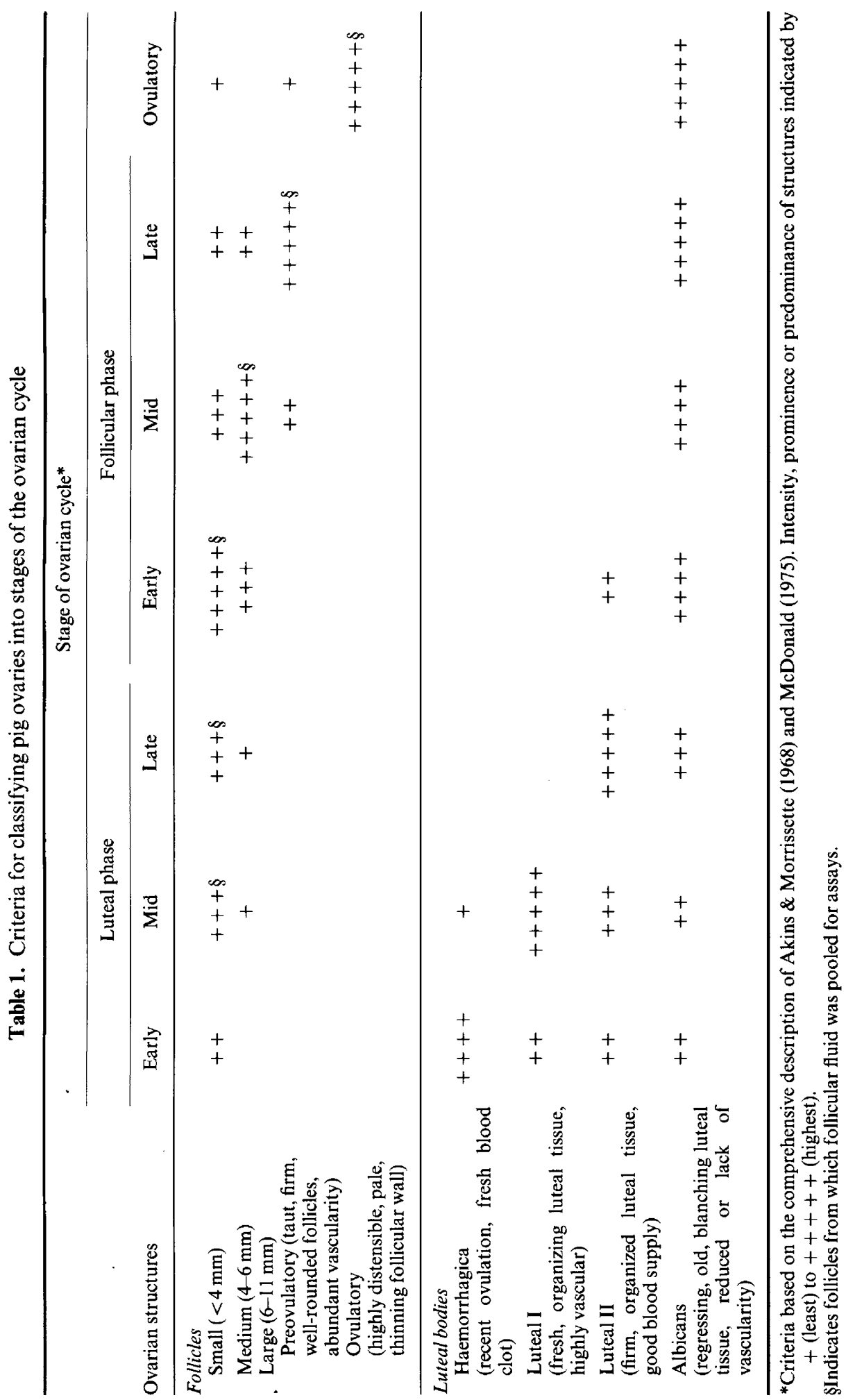


Table 2. Relationship of follicle size (diameter) to the ovarian cycle in pigs

\begin{tabular}{|c|c|c|c|}
\hline $\begin{array}{l}\text { Stage of } \\
\text { ovarian } \\
\text { cycle* }\end{array}$ & $\begin{array}{l}\text { Pairs of ovaries } \\
\text { examined }\end{array}$ & $\begin{array}{l}\text { No. of follicles } \\
\text { measured } \dagger\end{array}$ & $\begin{array}{c}\text { Diam. of } \\
\text { predominant } \\
\text { follicles }(\mathrm{cm}) \ddagger\end{array}$ \\
\hline \multicolumn{4}{|l|}{ Luteal } \\
\hline Early & - & - & - \\
\hline Mid & 5 & 60 & $0.27 \pm 0.03$ \\
\hline Late & 5 & 82 & $0.33 \pm 0.05^{\mathrm{a}}$ \\
\hline \multicolumn{4}{|l|}{ Follicular } \\
\hline Early & 5 & 72 & $0.46 \pm 0.04^{\mathrm{b}}$ \\
\hline Mid & 7 & 112 & $0.52 \pm 0.05^{\mathrm{a}}$ \\
\hline Late & 5 & 72 & $0.82 \pm 0.07^{\mathrm{b}}$ \\
\hline Ovulatory & 4 & 38 & $0.85 \pm 0.13$ \\
\hline
\end{tabular}

estimation of the functional stages of the cycle may suffice and, as we have seen in this study, can reasonably be made based on cyclic changes in the anatomy of the ovary (Akins \& Morrissette, 1968; McDonald, 1975).

Our findings of follicular steroid changes with functional stages of the ovarian cycle agree with results that utilized follicular fluid obtained surgically, every 3 days, throughout the oestrous cycle of living sows (Eiler \& Nalbandov, 1977), and thus support the use, in this context, of abattoirobtained ovaries. Although there may be some variation in morphological and biochemical development of follicles within sows as shown in weaned sows (Foxcroft \& Hunter, 1985; Foxcroft et al, 1987), generally, when follicular fluid from macroscopically similar follicles was pooled (to obtain aggregate effects) for assay as in the present study, steroid hormone concentrations were unchanged from the luteal through the early follicular stage. It has been previously reported that androgen and oestrogen concentrations did not change until the 16th day of the oestrous cycle in cyclic sows (Eiler \& Nalbandov, 1977; Pzala et al., 1985), which corresponds to the early follicular phase of our classification of pig ovaries when the follicles are $<5.0 \mathrm{~mm}$ in diameter.

The most dramatic changes in the follicular concentrations of steroids occurred in the later stages of the ovarian cycle. Follicular growth has been reported to be most rapid at this period (McDonald, 1975; Brinkley, 1981) and, in agreement with this observation, the greatest increase in mean follicular size occurred in mid- to late follicular-phase ovaries in our samples. The concentrations of all steroids increased sharply at this time, further confirming that follicular steroid values increased with growth (size) of developing follicles (Chang et al., 1976; Eiler \& Nalbandov, 1977; Henderson et al., 1982).

It is now well documented for several species that a tremendous alteration in steroidogenesis occurs in follicles following the ovulatory LH surge, characterized by a sharp drop in androgen and oestrogen secretion and a rededication of the steroid machinery to progesterone production (Moor, 1974; Hillensjo et al., 1976; Ahren et al., 1979; Saidapur \& Greenwald, 1979). This alteration of ovarian steroidogenesis has been found to be due to the inhibition of the $17 \alpha$-hydroxylase/17-20lyase enzyme (Suzuki \& Tamaoki, 1983). However, studies on ovulatory follicles of pigs were inconclusive because PMSG/hCG treatment of gilts resulted in increased follicular progesterone, decreased oestrogen and no change in androgen concentrations close to ovulation (Ainsworth $e t$ al., 1981). In contrast, during the normal cycle, the concentrations of all steroids measured, including progestagens, declined close to ovulation (Eiler \& Nalbandov, 1977). We found that follicles 

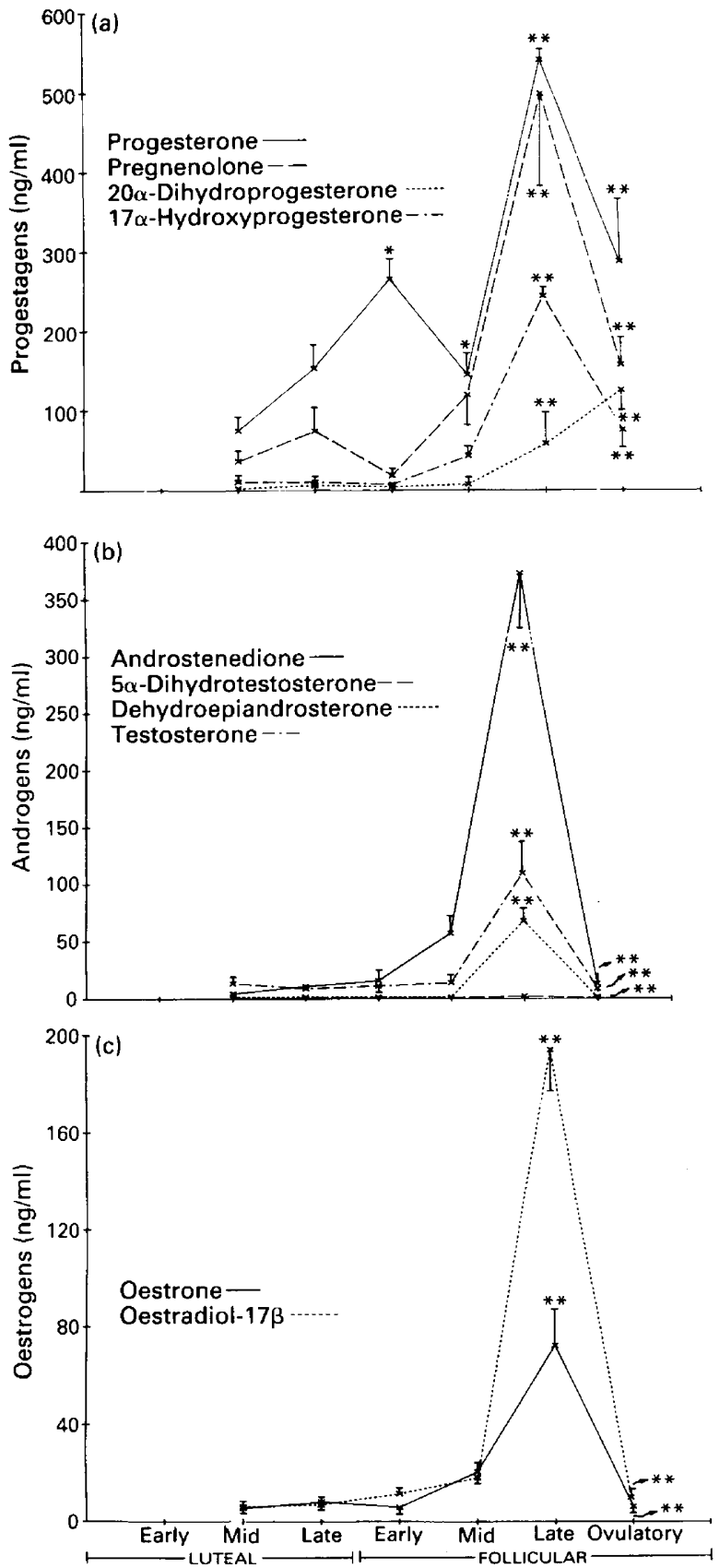

Fig. 1. Changes in the concentrations of follicular progestagens (a), androgens (b) and oestrogens (c) during the ovarian cycle of the pig. Values are means \pm s.e.m. (vertical bars) for $\geqslant 4$ observations (i.e. the no. of animals or pairs of ovaries in each group). ${ }^{*} P<0.05 ;{ }^{* *} P<0.001$ when the concentration of the same hormone is compared to the value in the immediately preceding stage of the ovarian cycle. 
categorized as ovulatory contained a pattern of steroids in agreement with that in the spontaneously ovulating animals (Eiler \& Nalbandov, 1977). Steroid concentrations declined significantly at ovulation, i.e. progestagen values declined by $45-70 \%$ while the concentrations of androgens and oestrogens were reduced by more than $90 \%$. Furthermore, because a larger number of individual steroids were measured in the present study, it was possible to determine that $20 \alpha-$ dihydroprogesterone concentrations did not decrease as did the other progestagens but instead were significantly elevated. Ovarian $20 \alpha$-hydroxysteroid dehydrogenase (20 $\alpha$-HSD) activity increases concomitantly with a decrease in the activity of the 17 $\alpha$-hydroxylase/17-20-lyase enzyme after exposure of rats to ovulatory amounts of exogenous or endogenous gonadotrophins (Suzuki \& Tamaoki, 1979; Eckstein et al., 1985; Tsafriri \& Eckstein, 1986). Our results with ovulatory follicles further support these enzyme studies, as we found a significant elevation in the product of $20 \alpha$-HSD activity, 20 $\alpha$-dihydroprogesterone, concomitant with a significant drop in the concentration of $17 \alpha$-hydroxyprogesterone, the product of the $17 \alpha$-hydroxylase enzyme.

The present findings agree with and, in terms of steroid profiles, extend existing studies that utilized ovaries from living sows with accurately dated oestrous cycles. In contrast, our results differ from findings on follicles from PMSG/hCG-treated prepubertal gilts, suggesting that, as in rats (Aguado \& Ojeda, 1985), exogenous, non-homologous gonadotrophin stimulation in pigs produces an ovarian steroidogenic response different from that in naturally cycling animals. However, it has been shown that ovaries of immature gilts are functionally different from ovaries of mature females (Channing \& Ledwitz-Rigby, 1975). Therefore, effects of age and parity cannot be ruled out. The inclusion in the present study of pregnenolone, 20 $\alpha$-dihydroprogesterone, $17 \alpha-$ hydroxyprogesterone, dehydroepiandrosterone and $5 \alpha$-dihydrotestosterone, which are known to occur in the steroidogenic pathway, and values of which have not been previously reported for pig follicles, provide a more comprehensive overview of steroid hormone production in the developing pig ovarian follicle.

We thank Mr Peter Villari and Mr Mike Villari and the entire staff of Peter D. Villari, Inc., of Philadelphia for their continued co-operation and generosity in donating the ovaries used in this study; Dr George L. Flickinger (Department of Obstetrics and Gynecology, University of Pennsylvania) for invaluable advice during the establishment of the radioimmunoassay systems; and Ms Ellen Behrend and Ms Doris S. Boyer for assistance during the preparation of this manuscript.

This work was supported by USDA Grant Section 1433 Formula Funds and the Pennsylvania Pork Producers Council. G.O.B. is on study leave from the Department of Veterinary Surgery and Reproduction, University of Ibadan, Nigeria.

\section{References}

Abraham, G.E. (1975) Radioimmunoassay of steroids in biological fluids. J. Steroid Biochem. 6, 261-270.

Abraham, G.E., Manlimos, F.S., Garza, R. \& Maroulis, G.B. (1975) Combined radioimmunoassay of four steroids in one $\mathrm{ml}$ of plasma. I. Progestins. Clin. Biochem. 8, 369-373.

Aguado, L.I. \& Ojeda, S.R. (1985) Physiological prepubertal activation of the ovary is not reproduced by pregnant mare serum gonadotropin (PMSG) administration. Proc. Soc. exp. Biol. Med. 178, 121-125.

Ahren, K., Hamberger, L., Hillensjo, T., Nilsson, L. \& Nordenstrom, K. (1979) Control of steroidogenesis in the preovulatory rat follicles. J. Steroid Biochem. 11, $791-798$.

Ainsworth, L., Tsang, B.K., Downey, B.R., Marcus, G.J. \& Armstrong, D.T. (1980) Interrelationship between follicular fluid steroid levels, gonadotropic stimuli and oocyte maturation during preovulatory development of porcine follicles. Biol. Reprod. 23, 621-627.

Akins, E.L. \& Morrissette, M.C. (1968) Gross ovarian changes during estrous cycle of swine. Am.J. vet. Res. 29, 1953-1957.

Brinkley, H.J. (1981) Endocrine signaling and female reproduction. Biol. Reprod. 24, 22-43.

Carr, B.R., Mikhail, G. \& Flickinger, G.L. (1971) Column chromatography of steroids on SephadexLH20. J. clin. Endocr. Metab. 33, 358-361.

Chang, S.C.S., Jones, J.D., Ellefson, R.D. \& Ryan, R.J. (1976) The porcine ovarian follicle: I. Selected chemical analysis of follicular fluid at different developmental stages. Biol. Reprod. 15, 321-328.

Channing, C.P. \& Ledwitz-Rigby, F. (1975) Methods for 
assessing hormone-mediated differentiation of ovarian cells in culture and in short term incubations. Methods in Enzymology 39, 183-230.

Eckstein, B., Greenbaum, D. \& Cohen, S. (1985) Kinetic studies on ovarian C-17, 20-lyase activity. Effect of luteinizing hormone surge. Endocrinology 117, $2376-2382$.

Eiler, H. \& Nalbandov, A.V. (1977) Sex steroids in follicular fluid and blood plasma during the estrous cycle of pigs. Endocrinology 100, 331-338.

Fernandez-Pardal, J., Gimeno, M.F. \& Gimeno, A.L. (1986) Catecholamines in sow graafian follicles at proestrus and at diestrus. Biol. Reprod. 34, 439-445.

Flemming, A.D. \& McGaughey, R.W. (1982) A progesterone binding component in porcine ovarian follicular fluid. J. Endocr. 94, 69-76.

Foxcroft, G.R. \& Hunter, M.G. (1985) Basic physiology of follicular maturation in the pig. J. Reprod. Fert., Suppl. 33, 1-19.

Foxcroft, G.R., Shaw, H.J., Hunter, M.G., Booth, P.J. \& Lancaster, R.T. (1987) Relationships between luteinizing hormone, follicle stimulating hormone and prolactin secretion and ovarian follicular development in the weaned sow. Biol. Reprod. 36, 175-191.

Gower, D.B. \& Cooke, G.M. (1983) Regulation of steroid transforming enzymes by endogenous steroids. $J$. Steroid Biochem. 19, 1527-1556.

Henderson, K.M., McNeilly, A.S. \& Swantson, I.A. (1982) Gonadotrophin and steroid concentrations in bovine follicular fluid and their relationship to follicular size. J. Reprod. Fert. 65, 467-473.

Hillensjo, T., Bauminger, S. \& Ahren, K. (1976) Effect of LH on the pattern of steroid production by preovulatory follicles of PMSG-injected immature rats. Endocrinology 99, 996-1002.

Hunter, R.H.F. (1967) Porcine ovulation after injection of human chorionic gonadotrophin. Vet. Rec. 81, 21-23.

Leung, C.P.K. \& Armstrong, D.T. (1980) Interactions of steroids and gonadotropins in the control of steroidogenesis in the ovarian follicle. Ann. Rev. Physiol. 42, $71-82$.

Lipner, H. \& Wendelken, L. (1971) Inhibition of ovulation by inhibition of steroidogenesis in immature rats. Proc. Soc. exp. Biol. Med. 136, 1141-1145.

Maxson, W.S., Haney, A.F. \& Schomberg, D.W. (1985) Steroidogenesis in porcine atretic follicles: loss of aromatase activity in isolated granulosa and theca. Biol. Reprod. 33, 495-501.

McDonald, L.E. (1975) Veterinary Endocrinology and Reproduction, 2nd edn, pp. $283-285$. Lea \& Febiger, Philadelphia.
MeNatty, K.P., Smith, D.M., Makris, A., Osathanondh, R. \& Ryan, K.J. (1979) The microenvironment of the human antral follicle: interrelationships among the steroid levels in antral fluid, the population of granulosa cells and the status of the oocyte in vivo and in vitro. J. clin. Endocr. Metab. 49, 851-860.

Moor, R.M. (1974) The ovarian follicle of the sheep: inhibition of oestrogen secretion by luteinizing hormone. J. Endocr. 61, 455-463.

Moor, R.M., Hay, M.F., Dott, H.M. \& Cran, D.C. (1978) Macroscopic identification and steroidogenic function of atretic follicles in sheep. J. Endocr. 77, 309-319.

Mori, T., Suzuki, A., Nishimura, T. \& Kambagawa, A. (1977) Inhibition of ovulation in immature rats by antiprogesterone antiserum. $J$. Endocr. 73, 185-186.

Pzala, J., Grazul, A., Wiesak, T., Muszynska, A. \& Dusza, L. (1985) Steroid hormone and prolactin in porcine follicular fluid in estrous cycle and early pregnancy. Expl Clin. Endocr. 86, 291-296.

Rodbard, D. (1974) Statistical quality control and routine data processing for radioimmunoassay and immunoradiometric assays. Clin. Chem. 20, 1255-1270.

Rondell, P. (1974) Role of steroid synthesis in the process of ovulation. Biol. Reprod. 10, 199-215.

Saidapur,S.K. \& Greenwald, G.S.(1979) Ovarian steroidogenesis in the proestrus hamster. Biol. Reprod. 20, $226-234$.

Sanyal, J.K., Berger, M.J., Thompson, I.E., Taymor, M.L. \& Horne, H.W., Jr (1974) Development of graafian follicles in adult human ovary. I. Correlation of estrogen and progesterone concentration in antral fluids with growth of follicles. J. clin. Endocr. Metab. 38, 828-835.

Suzuki, K. \& Tamaoki, B. (1979) Enzymological studies of rat luteinized ovaries in relation to acute reduction of aromatizable androgen formation and stimulated production of progestins. Endocrinology 104, 1317-1323.

Suzuki, K. \& Tamaoki, B. (1983) Acute decrease by human chorionic gonadotropin of the activity of preovulatory ovarian $17 \alpha$-hydroxylase and C-17,20lyase is due to decrease of microsomal cytochrome P-450 through de novo synthesis of ribonucleic acid and protein. Endocrinology 113, 1985-1991.

Tsafriri, A. \& Eckstein, B. (1986) Changes in follicular steroidogenic enzymes following the preovulatory surge of gonadotropins and experimentally-induced atresia. Biol. Reprod. 34, 783-787.

Received 13 November 1987 